\title{
On Decision Making in Connection with Optimal Anti- collision Manoeuvres by High Speed Craft in Waters Congested by Conventional Speed Vessels
}

\author{
Egil PEDERSEN***, Kinzo INOUE* and Masanori TSUGANE***
}

\begin{abstract}
The collision risk to multiple targets and identification of feasible evasive manoeuvres can be assessed simultaneously by judging the tip of own ship's velocity vector in relation to the display of collision danger lines and cone-shaped collision danger regions to acquired targets in true motion representation. This visual technique for collision avoidance assessment is referred to as the Collision Danger Presentation (CDP) technique. Possible benefits of the CDP technique for High Speed Craft (HSC) navigation have been evaluated by a simulator test programme with own ship operating at 45 knots in congested traffic conditions in Osaka Bay under restricted visibility. 4 experienced HSC navigators and 4 maritime university students with license participated in the evaluation. It was shown that judgement of evasive manoeuvres based on the CDP technique is superior to standard ARPA and is thus capable of enhancing navigational safety for HSC operations.
\end{abstract}

\section{Introduction}

High Speed Craft (HSC) are utilised in most sectors of maritime operation such as for example passenger and cargo carrying, leisure and military purposes. Although the majority of HSC are smaller vessels in the nominal speed range of 30 -40 knots, the increasing demand for high speed transportation has in recent years launched ocean -going HSC with lengths exceeding $100 \mathrm{~m}$ and speeds of $40+$ knots.

Collision avoidance is a key operative task for the HSC navigator. The traffic density in some areas in which HSC operate may be tremendous as for example is the case in the Inland Sea of Japan. The time factor is critical in order to make necessary target identification and to assess the risk of collision, and this can be greatly compressed.

The standard ARPA radar provides a graphical presentation of true and relative velocity vector and alpha-numeric display of minimum distance at, and time to, the closest point of approach, range, bearing, speed and course for targets acquired. True motion representation of the acquired traffic condition is the preferred display for anti-collision judgement among most HSC navigators. However, congested waterways and corresponding vector and alpha-numeric representation can easily impose a workload on the navigator which represents an increased risk for misjudgement and mistakes. The human ability to process alpha-numeric data in particular is limited, especially for high speed operations in congested waters.

An alternative display of anti-collision information is the Collision Danger Presentation (CDP) technique ${ }^{(1)}$ that can be derived by geometrical interpretation of velocity vectors in a collision scenario. Collision danger lines and cone -shaped collision danger regions can be displayed to acquired targets in true vector representation from which collision risk is judged by inspecting the tip of own ship's vector in relation to the collision danger lines and regions. A simulator study ${ }^{(1)}$ with conventional marine traffic indicated

* Member : Kobe University of Mercantile Marine (5-1-1, Fukae-minami, Higashi-Nada, Kobe 650-0022)

** Member : Norwegian University of Science and Technology (O. Nielsens v. 10, N-7491 Trondheim, Norway)

***Member : Japan Marine Science Inc. (Koike Bldg. No. 7, 2-3-6 Minamishinagawa, Tokyo 140-0004) 
that the CDP technique is capable of significantly improving the mariner's ability in judging collision avoidance to multiple targets.

This paper concerns a simulator test programme composed of congested traffic scenarios with own ship as a HSC travelling at a nominal speed of 45 knots between Kobe and Kansai International Airport. Comparing minimum passing distances and track lines of own ship show that the participants performed significantly more homogeneous, safe and precise manoeuvres when judging anti-collision based on the CDP technique than utilising standard ARPA.

\section{Theory}

The collision danger line (CDL) is created by parallel displacement of the bearing line to a target $i$, a distance equal to the length of targets true velocity vector $V_{i}$, and is therefore independent of own ship's motion parameters, see Figure 1. A minimum allowed distance (CPA limit) at Closest Point of Approach can be set at the interception between the CDL and end point (A) of the target's true vector, thereby forming a collision danger circle where the CPA limit is equal to the radius of the circle. Two lines are created from the circle, as opposing tangents to the circle, to the end point (B) of the CDL, whereby a collision danger sector (CDS) is created and displayed by the coned shaped area of the collision danger circle and the two lines, see Figure 2.

If the tip of own vessel's true vector is inside the CDS, and the speed and/or course are not altered, then the target will pass inside the predetermined minimum distance at closest point of approach. Any manoeuvre which deflects the end of own ship's vector out of the CDS will be a potential evasive manoeuvre.

The end co-ordinates (A and B) of the collision danger line are depending on the relative position, length and direction of the targets velocity vector. Let $V_{i}$ and $\psi_{i}$ represent the scalar true speed and course of target $i$, respectively, and $\Delta t$ is the time scale of vector length. $\boldsymbol{X}_{0}=\left[\begin{array}{ll}X_{0} & Y_{0}\end{array}\right]^{\mathrm{T}}$ and $\boldsymbol{X}_{i}=\left[X_{i}\right.$ $\left.Y_{i}\right]^{\mathrm{T}}$ are the position vectors of own ship and target, respectively. The CDL is then determined by,

$$
\boldsymbol{X}_{A_{i}}=\left[\begin{array}{ll}
X_{A i} & Y_{A i}
\end{array}\right]^{\mathrm{T}}=\boldsymbol{X}_{i}+V_{i} \Delta t \boldsymbol{I} \Psi_{i}
$$

and

$$
\boldsymbol{X}_{B_{i}}=\left[\begin{array}{ll}
X_{B_{i}} & Y_{B_{i}}
\end{array}\right]^{\mathrm{T}}=\boldsymbol{X}_{0}+V_{i} \Delta t \boldsymbol{I} \Psi_{i}
$$

where $\Psi_{i}=\left[\begin{array}{lll}\sin \psi_{i} & \cos \psi_{i}\end{array}\right]^{\mathrm{T}}$ and $\boldsymbol{I}=\left[\begin{array}{ll}(1 & 0\end{array}\right)^{\mathrm{T}}(0$ 1) $\left.{ }^{\mathrm{T}}\right]$ for $\left.0<\psi_{i}<\pi / 2, \boldsymbol{I}=\left[\begin{array}{llll}(1 & 0\end{array}\right)^{\mathrm{T}}\left(\begin{array}{ll}0 & -1\end{array}\right)^{\mathrm{T}}\right]$ for $\left.\pi / 2<\psi_{i}<\pi, \quad I=\left[\begin{array}{llll}-1 & 0\end{array}\right)^{\mathrm{T}}\left(\begin{array}{ll}0 & -1\end{array}\right)^{\mathrm{T}}\right]$ for $\pi<$ $\psi_{i}<3 \pi / 2$ and $\left.\boldsymbol{I}=\left[\begin{array}{llll}(-1 & 0\end{array}\right)^{\mathrm{T}}\left(\begin{array}{ll}0 & 1\end{array}\right)^{\mathrm{T}}\right]$ for $3 \pi / 2<$ $\psi_{i}<2 \pi$.

The co-ordinates $(\mathrm{C}$ and $\mathrm{D})$ for the tangents to the CPA limit circle is dependent on the orientation of the CDL and can be formulated as,

$$
\boldsymbol{X}_{C i}=\boldsymbol{X}_{B i}+(-1)^{k}\left|\boldsymbol{X}_{A B i}\right|^{2}-\mathrm{CPA}^{2}{ }^{2}{ }_{\text {ilm }} \Omega_{i}
$$

and

$$
\boldsymbol{X}_{D i}=\boldsymbol{X}_{B i}+(-1)^{n}\left|\boldsymbol{X}_{A B i}\right|^{2}-\mathrm{CPA}^{2}{ }_{1 \mathrm{im}} \Omega_{i}
$$

where $\left|\boldsymbol{X}_{A B i}\right|$ is the scalar length between $\mathrm{A}$ and $\mathrm{B}, \mathrm{CPA}_{1 \mathrm{im}}$ is the selected limit of passing distance

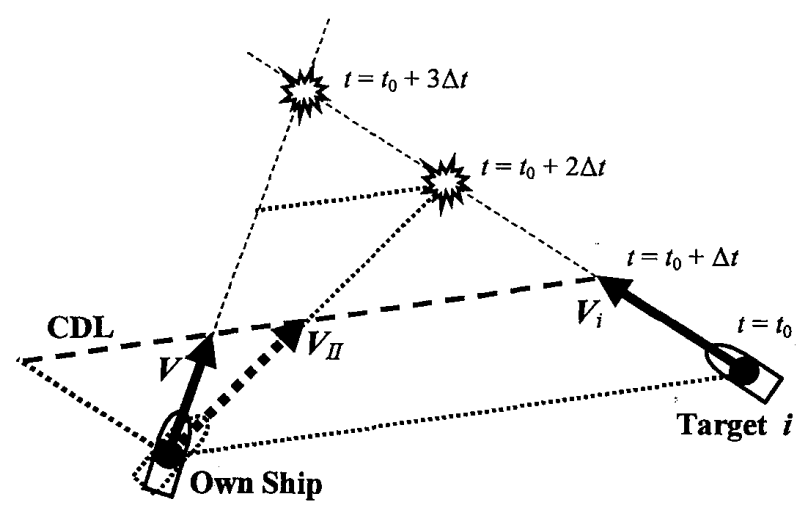

Figure 1 Own ship and target on collision course if own ship's vector equals $\boldsymbol{V}$ or $\boldsymbol{V}_{I I}$. $(\mathrm{CDL}=$ Collision Danger Line.)

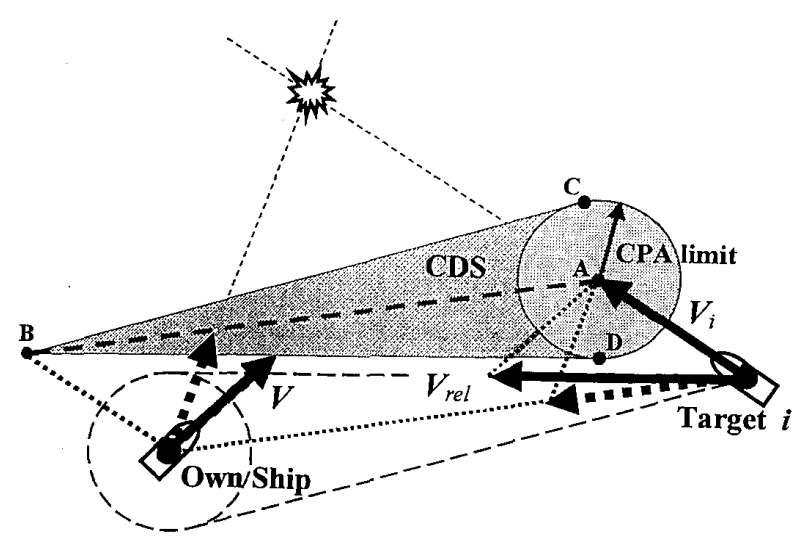

Figure 2 Own ship $(\boldsymbol{V})$ will pass astern of target with a distance equal selected CPA limit. The shadowed cone-shaped region represents the Collision Danger Sector (CDS) as it appears in true motion display. 
at closest point of approach, and $\Omega_{i}=[\cos (\gamma+$ $\left.\left.(-1)^{m} \beta\right)_{i} \sin \left(\gamma+(-1)^{p} \beta\right)_{i}\right]^{\mathrm{T}}$ with $\gamma=\tan ^{-1}$ $\left[\left(Y_{A i}-Y_{B i}\right) /\left(X_{A i}-X_{B i}\right)\right]$ and $\beta=\tan ^{-1}\left[\mathrm{CPA}_{1 \mathrm{im}} /\right.$ $\left.\left|\boldsymbol{X}_{A B i}\right|\right] . k, m, n$ and $p$ are integers (0 or 1 ).

\section{Experiment}

4 final-year maritime students and 4 experienced HSC navigators participated in a test programme utilising the ship handling simulator facility of Kobe University of Mercantile Marine. Two scenarios with high traffic densities were carried out in Osaka Bay between Kobe and Kansai International Airport.

The own ship employed was the $\mathrm{K}$-Jet hydrofoil craft operating with a nominal speed of 45 knots. Other ships were encountered in succession from port and starboard sides according to the most commonly used ship traffic routes in this sector of Osaka Bay. All targets kept constant speed and course.

A daylight scene with restricted visibility of $0.5 \mathrm{n}$. miles was created in the external world scene of the simulator. The environmental conditions were no wind or current.

Tables 1 and 2 show the details of traffic set-up for the scenarios. (Bold figures represent changes in traffic set-up prior between student and experienced participants.) Figures 3 through 8 show the ARPA and CDP displays available at the position from which own ship was allowed to make an evasive manoeuvre, i. e. time $=120 \mathrm{sec}$ from initial time. The base position $(x=0, y=0)$ of the scenarios was $\mathrm{N} 34^{\circ} 40.25^{\prime} \mathrm{E} 135^{\circ} 10.25^{\prime}$.

The participants were numbered alphabetically according to their schedule on the simulator and familiarised with the CDP technique in an introductory session followed by practice trials on the simulator. All targets were pre-acquired prior to starting a scenario. Each participant was briefed explicitly on the monitored traffic situation.

The participants were required to keep a minimum passing distance (CPA limit) of $0.3 \mathrm{n}$. miles to all targets and to carry out evasive manoeuvres by course change with minimum deviation from original track line. All participants were able to perform the experimental trials, but candidate $\mathrm{A}$ could not attend the final part of the schedule
Table 1 Own ship and target data for the Kobe -Kansai scenario at initial position.

\begin{tabular}{|l|c|c|}
\hline $\begin{array}{c}\text { Type } \\
\text { of } \\
\text { Vessel }\end{array}$ & $\begin{array}{c}\text { Initial Position } \\
\text { X, Y } \\
{[\mathrm{m}],[\mathrm{m}]}\end{array}$ & $\begin{array}{c}\text { Initial } \\
\text { Course/Speed } \\
{[\mathrm{deg}] /[\mathrm{m} / \mathrm{s}]}\end{array}$ \\
\hline K-Jet & $9723,-5043$ & $180.0 / 23.1$ \\
\hline Cargo 499 GT & $11713,-11999$ & $275.6 / 6.7$ \\
\hline BC 74k DWT & $13890,-12574$ & $275.3 / 7.7$ \\
\hline CC 3500 TEU & $12686,-13554$ & $227.0 / 8.2$ \\
\hline Cargo5kDWT & $11101,-15713$ & $229.5 / 7.2$ \\
\hline BC 74k DWT & $6605,-23318$ & $049.0 / 6.7$ \\
\hline Fishing boat & $3797,-23625$ & $107.4 / 6.2$ \\
\hline Fishing boat & $845,-22586$ & $107.9 / 6.2$ \\
\hline Tank 299 GT & $7498,-21072$ & $050.1 / 6.7$ \\
\hline CC 3500 TEU & $4547,-14813$ & $095.0 / 7.2$ \\
\hline Heavy-Lifter & $6575,-14673$ & $091.7 / 7.0$ \\
\hline Cargo 499 GT & $15922,-11759$ & $275.4 / 6.8$ \\
\hline Heavy-Lifter & $2756,-16035$ & $095.0 / 8.2$ \\
\hline CC 3500 TEU & $15725,-12490$ & $228.0 / 8.2$ \\
\hline CC 3500 TEU & $10069,-9817$ & $274.8 / 8.2$ \\
\hline Tank 6k DWT & $8439,-10548$ & $275.4 / 7.2$ \\
\hline LNGC & $2025,-13727$ & $095.1 / 7.7$ \\
\hline Cargo 499 GT & $9846,-15501$ & $228.3 / 8.2$ \\
\hline PCC 3500 & $4895,-23180$ & $049.2 / 6.7$ \\
\hline
\end{tabular}

Table 2 Own ship and target data for the Kansai -Kobe scenario at initial position.

\begin{tabular}{|l|c|c|}
\hline $\begin{array}{c}\text { Type } \\
\text { of } \\
\text { Vessel }\end{array}$ & $\begin{array}{c}\text { Initial Position } \\
\text { X, Y } \\
{[\mathrm{m}],[\mathrm{m}]}\end{array}$ & $\begin{array}{c}\text { Initial } \\
\text { Course/Speed } \\
{[\mathrm{deg} . / /[\mathrm{m} / \mathrm{s}]}\end{array}$ \\
\hline K-Jet & $10093,-27427$ & $000.0 / 23.1$ \\
\hline BC 74k DWT & $8612,-21164$ & $049.5 / 5.7(6.2)$ \\
\hline CC 3500TEU & $6189,-21637$ & $050.3 / 8.7$ \\
\hline Cargo5kDWT & $7871,-14673$ & $094.9 / 4.1$ \\
\hline Tank299GT & $3797,-10867$ & $082.0 / 6.8$ \\
\hline Ferry & $7032,-9942$ & $082.5 / 6.2(6.7)$ \\
\hline Fishing boat & $17133,-4398$ & $261.9 / 6.2$ \\
\hline Ferry & $16078,-5294$ & $262.2 / 7.7$ \\
\hline BC 74k DWT & $14911,-12516$ & $274.9 / 6.7$ \\
\hline Fishing boat & $17131,-13330$ & $275.4 / 6.5$ \\
\hline Heavy-Lifter & $11945,-14450$ & $227.6 / 7.0$ \\
\hline Ferry & $10352,-20508$ & $049.5 / 6.7(7.2)$ \\
\hline LNGC & $9565,-14207$ & $095.2 / 5.1$ \\
\hline PCC 3500 & $13616,-13700$ & $230.1 / 7.7$ \\
\hline Fishing boat & $13616,-4811$ & $261.7 / 6.8$ \\
\hline BC 74k DWT & $\mathbf{9 3 1 1 , - 1 9 6 1 8}$ & $050.9 / 7.2(7.7)$ \\
\hline RORO & $12828,-11900$ & $275.9 / 6.7$ \\
\hline LNGC & $5683,-9593$ & $081.6 / 6.2$ \\
\hline Heavy-Lifter & $\mathbf{1 0 9 4 2 , - 1 6 6 3 9}$ & $\mathbf{2 2 6 . 4 / 6 . 2}$ \\
\hline BC 70k DWT & $\mathbf{9 1 7 0 , - 1 7 0 3 2}$ & $\mathbf{2 2 8 . 3 / 6 . 2}$ \\
\hline LNGC & $\mathbf{5 8 5 1 , - 1 3 9 8 1}$ & $\mathbf{0 9 5 . 2 / 6 . 2}$ \\
\hline
\end{tabular}




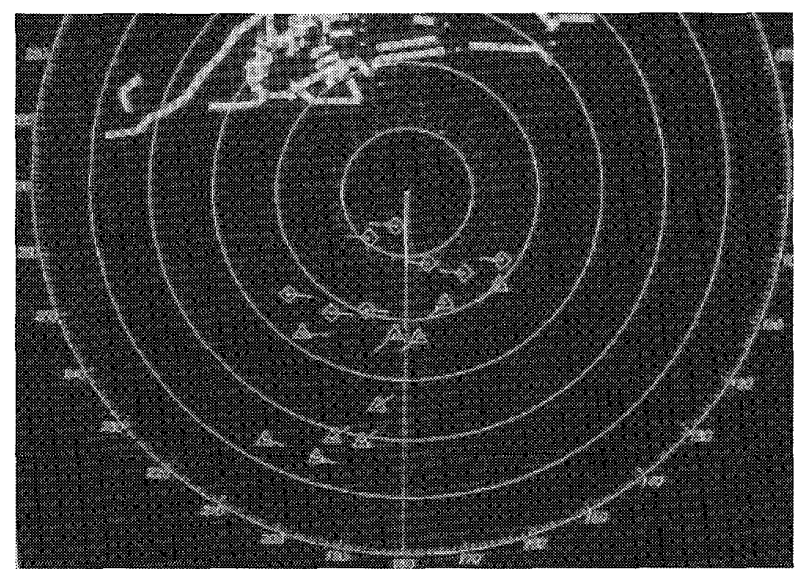

Figure 3 Kobe-Kansai scenario: True motion display of traffic condition. (Radar range $=12 \mathrm{n}$. miles.)

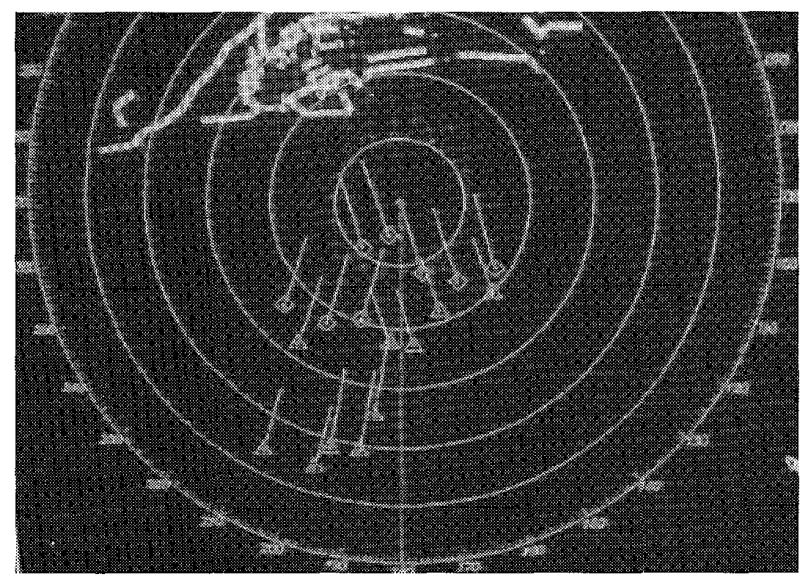

Figure 4 Kobe-Kansai scenario: Relative motion display of traffic condition. (Radar range $=12 \mathrm{n}$. miles.)

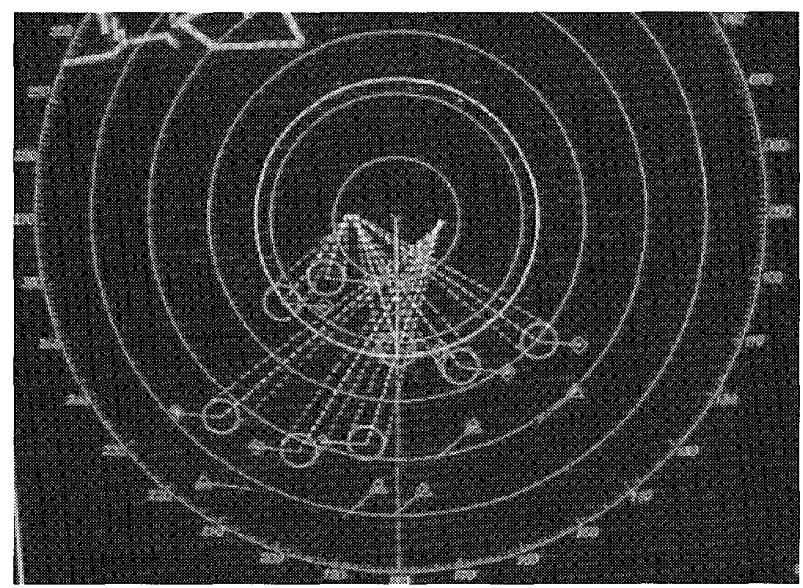

Figure 5 Kobe-Kansai scenario: CDP display of traffic condition. (Radar range $=6 \mathrm{n}$. miles., $\mathrm{CPA}$ limit $=0.3 \mathrm{n}$. miles.)

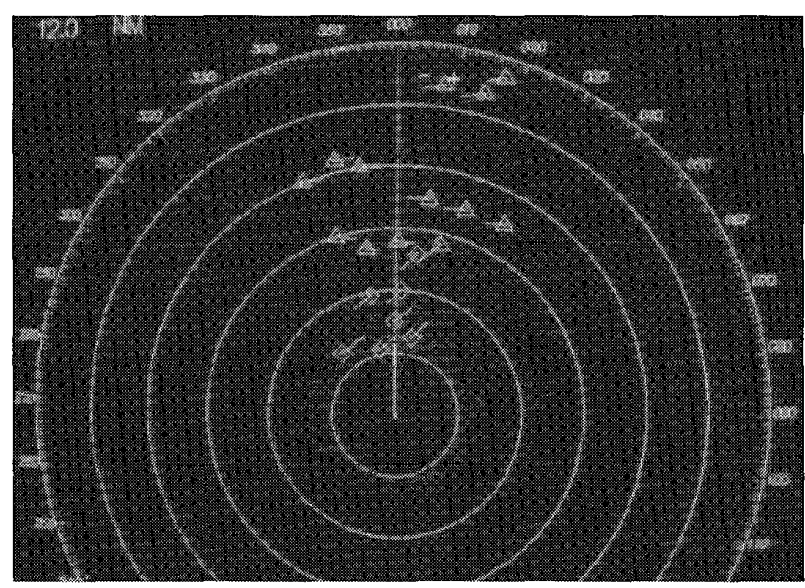

Figure 6 Kobe-Kansai scenario: True motion display of traffic condition. (Radar range $=12 \mathrm{n}$. miles.)

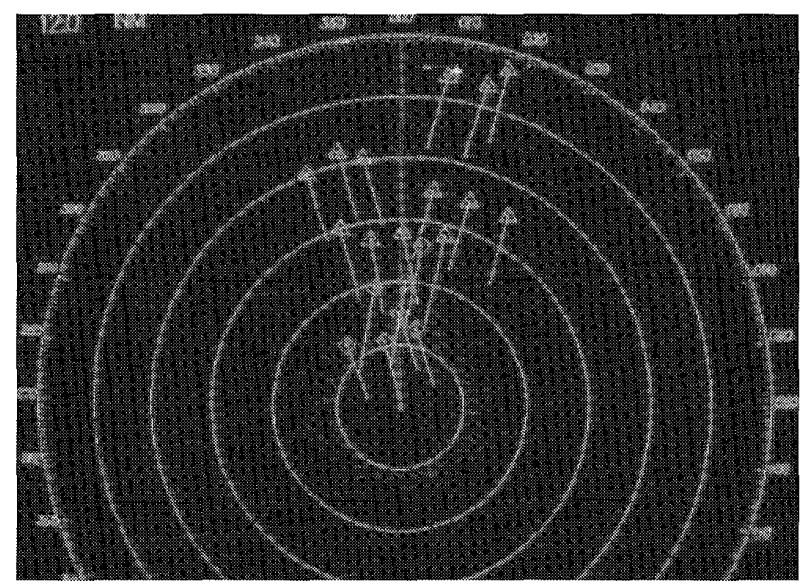

Figure 7 Kansai-Kobe scenario: Relative motion display of traffic condition. (Radar range $=12 \mathrm{n}$. miles.)

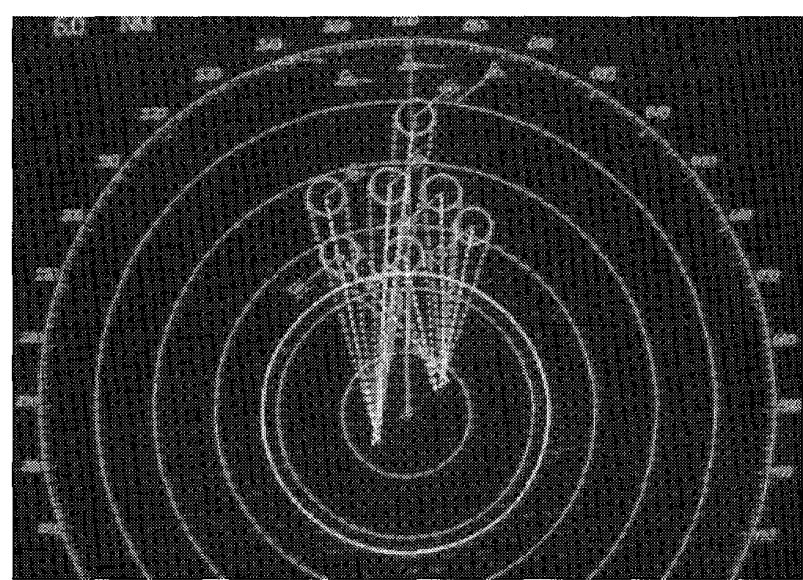

Figure 8 Kansai-Kobe scenario: CDP display of traffic condition. (Radar range $=6 \mathrm{n}$. miles., $\mathrm{CPA}$ limit $=0.3 \mathrm{n}$. miles.) 


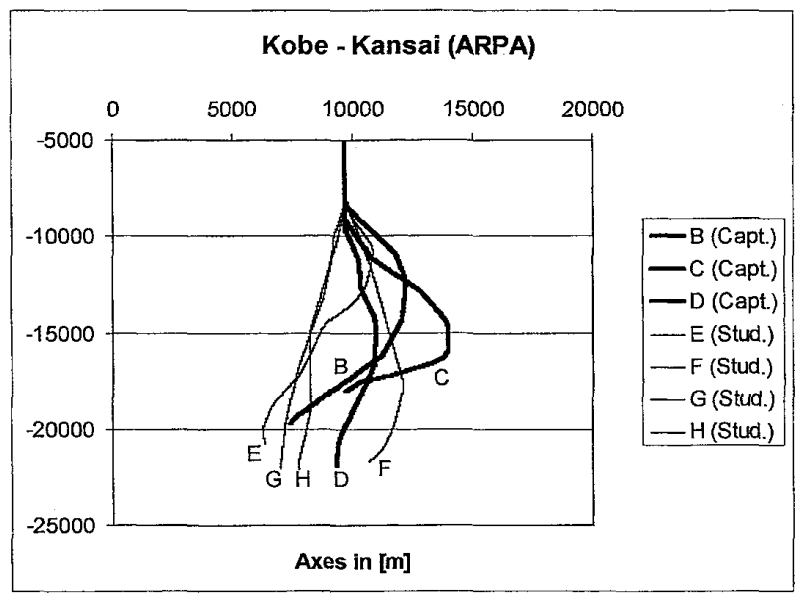

Figure 9 Kobe-Kansai (ARPA) scenario: Track lines of $\mathrm{K}$-Jet when judging anti - collision based on ARPA display.

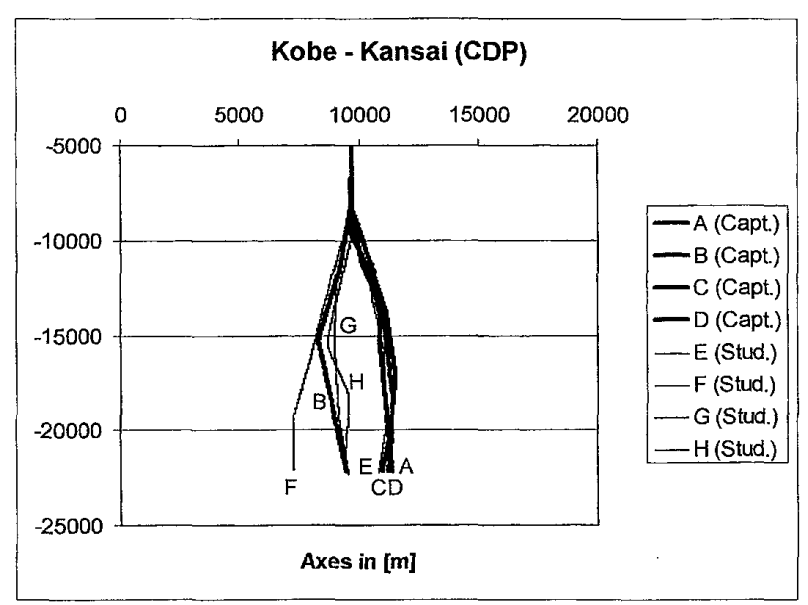

Figure 10 Kobe-Kansai (CDP) scenario: Track lines of $\mathrm{K}$-Jet when judging anti-collision based on CDP display.

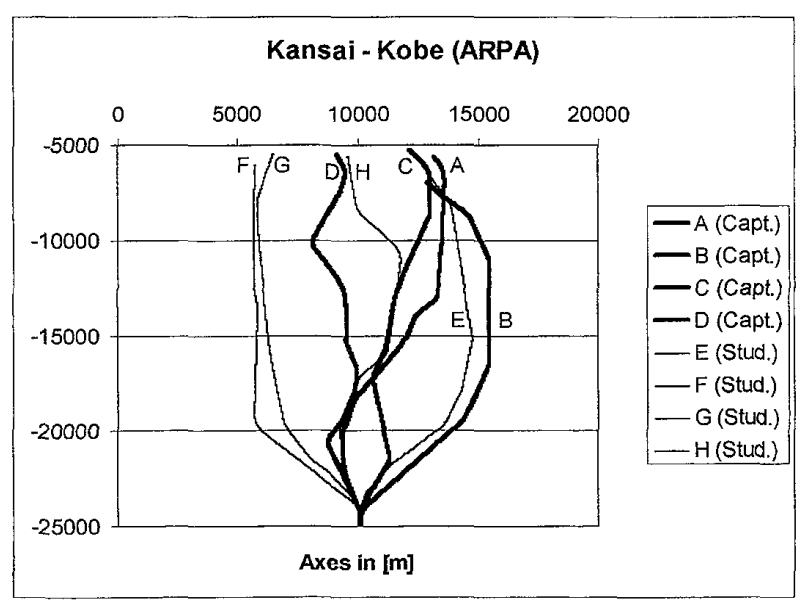

Figure 11 Kansai-Kobe (ARPA) scenario: Track lines of $\mathrm{K}$-Jet when judging anti-collision based on ARPA display.

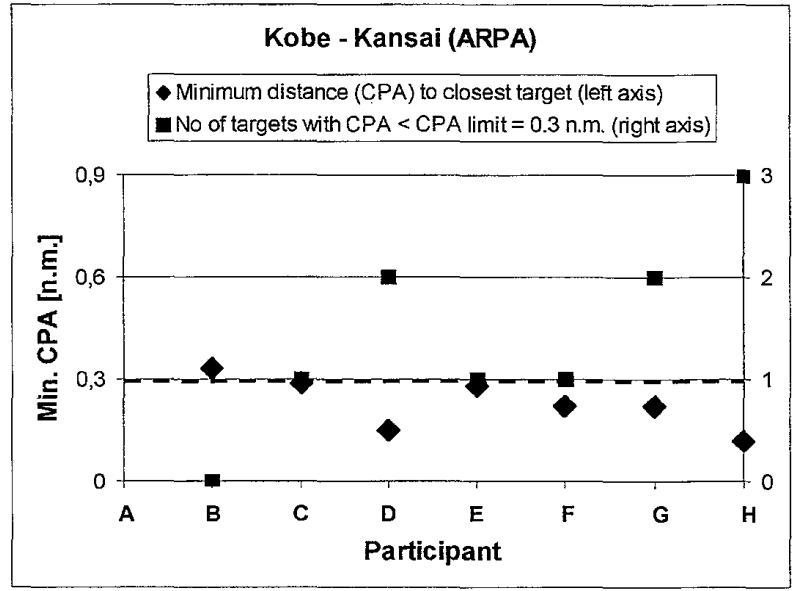

Figure 12 Kobe-Kansai (ARPA) scenario: Min. CPA to closest target and number of targets with min. CPA $<0.3$ n. miles.

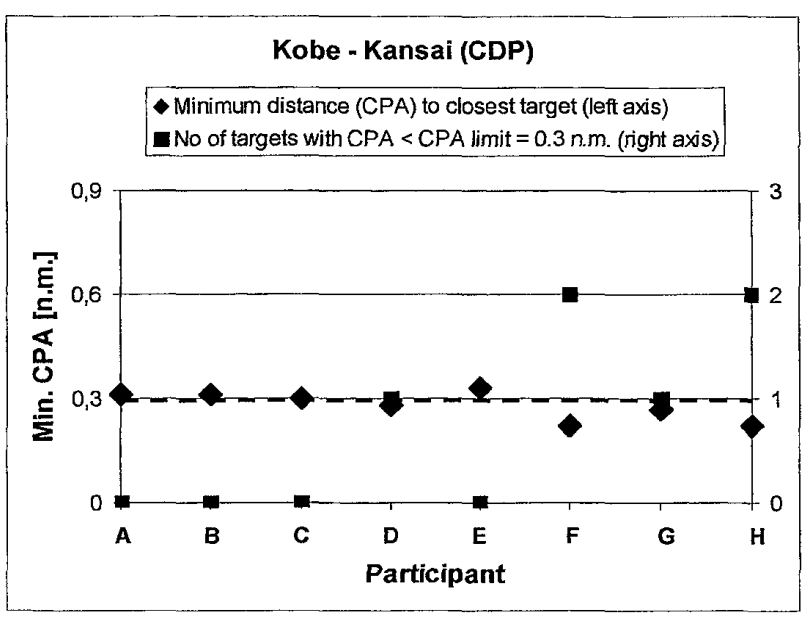

Figure 13 Kobe-Kansai (CDP) scenario: Min. CPA to closest target and number of targets with min. CPA $<0.3$ n. miles.

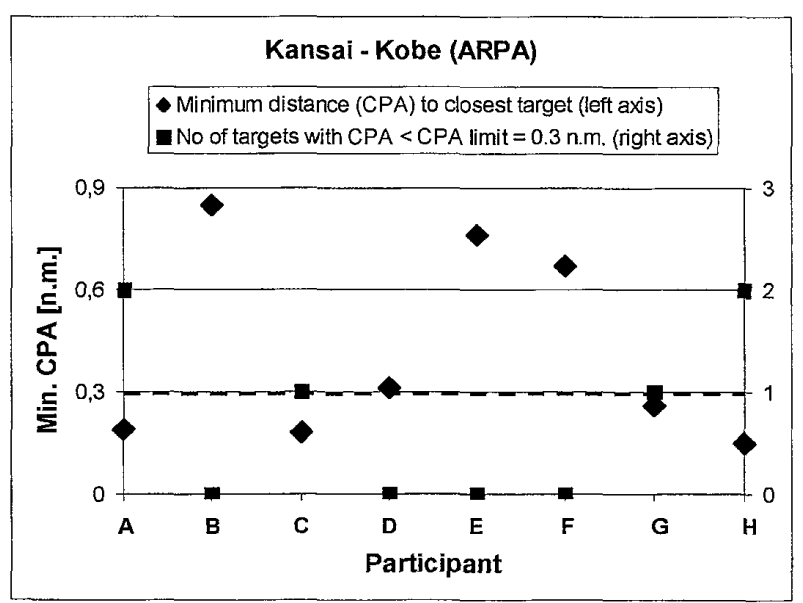

Figure 14 Kansai-Kobe (ARPA) scenario: Min. CPA to closest target and number of targets with min. CPA $<0.3 \mathrm{n}$. miles. 


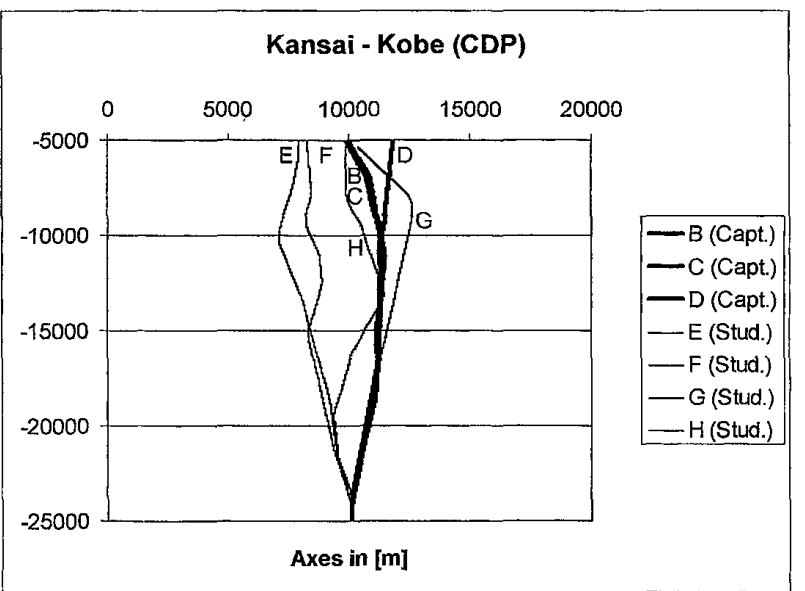

Figure 15 Kansai-Kobe (CDP) scenario: Track lines of $\mathrm{K}$-Jet when judging anti-collision based on CDP display.

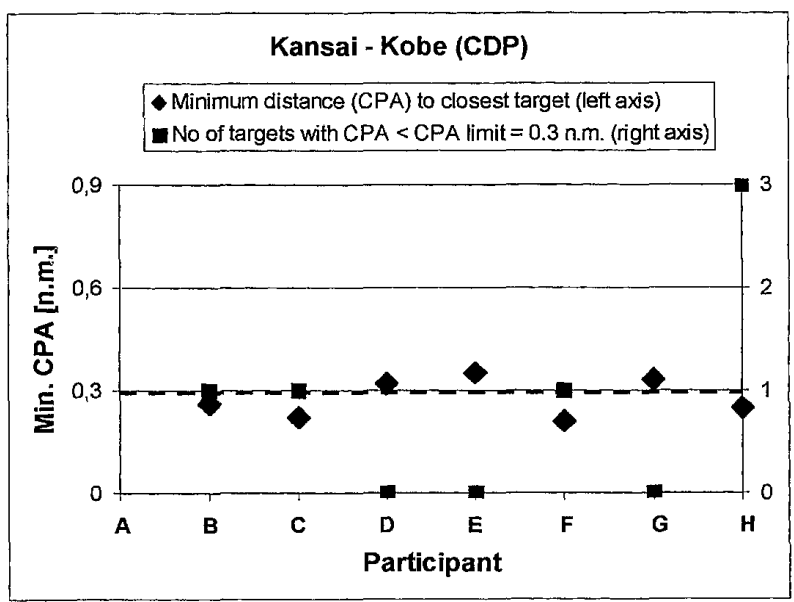

Figure 16 Kansai-Kobe (CDP) scenario: Min. $\mathrm{CPA}$ to closest target and number of targets with min. CPA $<0.3 \mathrm{n}$. miles.

which for the experienced group of participants (A, B, C, D) was carried out on a second day.

The results of the test programme are shown in Figures 9 through 16 and are presented as own ship's track line and minimum passing distance to the closest target for the individual participant in each scenario and number of targets with minimum $\mathrm{CPA}<\mathrm{CPA}$ limit.

\section{Discussion}

High Speed Craft (HSC) navigation in congested and confined waters impose a large degree of stress to the navigator. The excess speed compared to conventional speed vessels is the major reason why an HSC, in practice, give way in crossing situations even though it is technically the stand-on vessel according to the COLREGS. An HSC with speed at least twice as great as the surrounding traffic is in control of the navigation safety in view of the speed-aspect ratio so that a course not less than 30 degrees from the bearing of the slower vessel (s), collision will be avoided whatever course-evasive action the slower vessel (s) takes.

The results of the simulator test programme revealed the potential benefits of decision making based on the display of collision danger lines and regions in connection with optimal anti-collision manoeuvres by HSC in congested waters. The individual participants selected, in general, course changes with minimum deviations from original track line in order to obtain the required $\mathrm{CPA}$ limit when judging collision avoidance based on the CDP display. However, it was noticeable that participants $\mathrm{F}$ and $\mathrm{H}$, in particular, underestimated the importance of reducing the vector length with decreasing relative distances to be able to supervise the collision risk until passing the closest target (s). This failure caused the participants in question to make evasive manoeuvres in relation to more distant targets, thus violating the required minimum passing distance to the closest target (s).

The memory effect of the scenarios was taken into account by not informing the participants that each scenario was to be run twice, with and without CDP display, respectively. The schedule on the simulator was also on different days for some participants. In case of the experienced participants, more targets were added to the Kansai-Kobe scenario (Table 2) in order to increase the difficulty of anti-collision judgement by the CDP technique.

\section{Conclusions}

The simulator study with a High Speed Craft navigating in waters congested by conventional speed vessels has substantiated that anti-collision assessment by comparing the tip of own ship's velocity vector in relation to the true motion display of collision danger lines and cone-shaped collision regions, is superior to judgement by standard ARPA and is thus capable of enhancing 
navigation safety for HSC operations in congested waterways.

The benefits are the retention of true motion overview simultaneously with that collision risk to multiple targets and identification of possible evasive manoeuvres with minimum deviation from original track line can be judged visually. The homogeneous decision-making revealed between experienced and non-experienced HSC navigators by utilising this visualisation-based collision avoidance display enables the need for long-term experience in order to operate HSC safely from a collision avoidance viewpoint to be significantly reduced.

\section{Acknowledgements}

Sincere gratitude is expressed to Professor Dr Kiyoshi Hara, President of Kobe University of Mercantile Marine, for inviting the first author to carry out this research. The practical and technical support received from administrative and technical staff at KUMM is greatly appreciated. Sincere thanks are expressed to the Captains of the company operating the $\mathrm{K}$-Jet hydrofoil craft and students of KUMM that kindly participated in the simulator test programme. Financial support for this research has been received from the Norwegian University of Science and Technology.

\section{References}

(1) E. PEDERSEN, K. INOUE and M. TSUGANE (2002). Evaluation of a Radar Plot and Display Technique for Anti-collision Assessment of Multiple Targets in True Vector Representation by Application of the Environmental Stress Model. J. Japan Institute of Navigation, 106, pp. 1-12.

\section{Questions and Answers}

Hideki HAGIWARA (Tokyo University of Mercantile Marine): Thank you very much for your presentation. Anti-collision manoeuvres should take into account the future action of target ships. In general, the HSC can easily cope with unpredicted future action of conventional speed vessels as it can adjust heading quickly. I can therefore understand the advantage of the proposed CDP technique for HSC. However, I would like to know how the CDP display is more efficient than ARPA display when own ship is a conventional speed vessel in congested waters.

Egil PEDERSEN : Thank you very much for your question. In our previous simulator study ${ }^{(1)}$ we considered conventional speed vessels in restricted waters with various traffic congestion. Own ship employed was a container ship operating with a nominal speed of 10-12 knots. It was shown that own ship took advantage of the CDP display with increasing complexity of the monitored traffic condition.

The retention of true motion overview simultaneously with that collision risk to multiple targets and identification of possible evasive manoeuvres are the core benefits of the CDP technique. These benefits apply to conventional speed vessels as well as HSC. However, the simulator studies revealed that anti-collision judgement by the CDP technique might cause a risk of minor and frequent course changes to be carried out as evasive manoeuvres. This tendency is related to the easiness in visual assessment of the tip of own ship's vector in relation to the displayed collision danger lines and regions in order to achieve a precise passing distance to the critical target (s).

Violation of the COLREGS with respect to distinct evasive manoeuvres in give-way situations might be considered for further research concerning the CDP technique. Although the technique is undoubtedly of more benefit for HSC than conventional speed vessels in view of the excess speed, I firmly believe the benefits outlined are of relevance for conventional speed operations provided violation of COLREGS are avoided. 